University of Nebraska - Lincoln

DigitalCommons@University of Nebraska - Lincoln

USDA National Wildlife Research Center - Staff

Publications

U.S. Department of Agriculture: Animal and Plant Health Inspection Service

May 2007

\title{
Mountain Beaver: A Primitive Fossorial Rodent
}

Wendy M. Arjo

USDA/APHIS/WS/National Wildlife Research Center

Follow this and additional works at: https://digitalcommons.unl.edu/icwdm_usdanwrc

Part of the Environmental Sciences Commons

Arjo, Wendy M., "Mountain Beaver: A Primitive Fossorial Rodent" (2007). USDA National Wildlife Research Center - Staff Publications. 675.

https://digitalcommons.unl.edu/icwdm_usdanwrc/675

This Article is brought to you for free and open access by the U.S. Department of Agriculture: Animal and Plant Health Inspection Service at DigitalCommons@University of Nebraska - Lincoln. It has been accepted for inclusion in USDA National Wildlife Research Center - Staff Publications by an authorized administrator of DigitalCommons@University of Nebraska - Lincoln. 


\section{Mountain Beaver: A Primitive Fossorial Rodent}

Wendy M. Arjo

\section{1 \\ Introduction}

As the largest mammalian order, rodents are nearly cosmopolitan in distribution, can exploit a broad spectrum of foods, and can often reach high population densities. One sole representative of the most primitive family of rodents, Aplodontidae, does not share some of these common rodent characteristics. The aplodontoid rodents in the family Aplodontidae and Mylagsulidae radiated during the Miocene from the Allomyinae family (Carraway and Verts 1993). The extinct Mylagaulidae represents the earlier radiation of these rodents who exhibited great specialization (Carraway and Verts 1993). Unlike the other members of the rodent order, mountain beavers are not prolific breeders; nor are they broad-spectrum habitat invaders, retaining in their morphology the primitive condition of the masseter muscle originating entirely on the zygomatic arch. The mostly extinct Aplodontidae family is now made up of the monotypic genus Aplodontia which has been able to survive since the early Oligocene and in some areas is even considered a pest.

Mountain beavers (Aplodontia rufa) are known from a variety of common names including boomer, whistler, and the Native American names sewellel and showt'l. Although the common name suggests relationship to true beaver (Castoridae), this semi-fossorial rodent shares only the behavior of tree clipping with the stream beaver and is usually more abundant at lower elevations than in mountainous areas. In Oregon, mountain beavers have retained the designation of boomer even though their vocalizations do not include booms or whistles. Very few people actually know about, much less have seen, this compact fossorial rodent. In this chapter I will present information on the ecology and human-wildlife conflicts of this little-known rodent species.

Wendy M. Arjo: USDA/APHIS/WS/National Wildlife Research Center, 9730-B Lathrop Industrial Dr., SW. Olympia, WA 98512, USA, E-mail: Wendy.M.Arjo@aphis.usda.gov 


\section{2}

\section{Distribution of the Aplodontidae Family}

The mountain beaver, endemic to western North America, is the only extant member of the family Aplodontidae. Considered the most primitive rodent species, mountain beavers have a restricted geographic distribution to western North America. Currently seven subspecies are recognized (Dalquest and Scheffer 1945; Hall 1981), with the largest distribution of a single subspecies (A. r. rufa) ranging from southern British Columbia, Canada through coastal Washington and into central Oregon. Contiguous with this population are three other subspecies including A. r. rainieri (Cascade Range of Washington, Oregon, and northern California), A. $r$. pacifica (Oregon and northwestern California coast), and A. r. humboldtiana (northern coastal California; Feldhamer et al. 2003). Three isolated mountain beaver populations occur in California. A. r. californica extends through much of the Sierra Nevada Range in eastern California into the western extreme portion of Nevada. The remaining two California populations are isolated along the northern coast at Point Arena, A. r. nigra, $\left(62 \mathrm{~km}^{2}\right)$ in Mendocino County (Steele 1986; Zielinski and Mazurek 2006) and Point Reyes, A. r. phaea, $\left(285 \mathrm{~km}^{2}\right)$ in Marin County (Fellers et al. 2004; Wake 2006).

Very little change in geographic distribution of the mountain beaver has occurred since the late Oligocene (Carraway and Verts 1993); however, climatic changes, physical geographic changes to the coast line, and fragmentation of boreal forest communities have likely contributed to the isolation of the southern coastal A. rufa subspecies at Point Arena and Point Reyes (Wake 2006). Recent recoveries of A. rufa in Duncan's Point Cave documented the historical distribution of the mountain beaver during the mid-Holocene likely extended further north of Point Reyes (Wake 2006). Currently the subspecies at Point Arena (A.r. nigra) is listed as federally endangered (United States Federal Registry, 56 FR 64716). In Canada, mountain beavers (A. r. rufa and A. r. rainieri) are designated as species of concern by the Committee on Status of Endangered Wildlife in Canada (sararegistry.gc.ca/species/).

\section{3}

\section{Mountain Beaver Ecology}

The general body conformation of the mountain beaver is cylindrical and compact (Feldhamer et al. 2003). Average adult length of $A$. rufa, without the stump-like tail, is $32 \mathrm{~cm}$, but can range from 30 to $50 \mathrm{~cm}$ (Feldhamer et al. 2003). Maximum adult body weight in the wild was reported to 
be $1.4 \mathrm{~kg}$ (Maser et al. 1981); however, in captivity weights up to $1.6 \mathrm{~kg}$ have been documented (Arjo, personal observation). In the field, average adult weight of the A. rufa subspecies is $1.0 \mathrm{~kg}$ (Arjo, unpublished data) which is also similar to weights for A. r. nigra (Zielinski and Mazurek 2006). Although mountain beavers spend a large portion of their time below ground, movement above ground does occur both during the day and at night (Ingles 1959; Arjo, unpublished data). Mountain beavers have low basal metabolic rates (McNab 1979) and their activity is often short in duration, followed by longer periods of inactivity (Ingles 1959; Arjo, personal observation).

Although the extensive burrow system used by the mountain beaver may offer some protection from predators, mountain beavers are prey to a large variety of predators. Striped (Spilogale gracilis) and spotted skunks (Mephitis mephitis), mink (Mustela vison), gray fox (Urocyon cinereoargenteus), raccoons (Procyon lotor), badgers (Taxidea taxus), bobcats (Lynx rufus), coyotes (Canis latrans), fisher (Martespennanti), long-tailed weasels (Mustela frenata), cougars (Puma concolor), and northern goshawks (Accipiter gentiles) have all been documented as predators on mountain beaver (Taylor 1918; Toweill and Maser 1985; Witmer and deCalesta 1986; Thrailkill et al. 2000; Arjo, unpublished data).

\subsection{1 Habitat}

Mountain beavers can be found up to $3,000 \mathrm{~m}$ elevation in portions of the Sierra Nevada Range; however, they are more commonly found at lower elevations in humid, densely vegetated understory areas (Feldhamer et al. 2003). Physiological constraints (e.g., inefficient kidneys; Pfeiffer et al. 1960) and the need for a constant water source likely limit the mountain beaver's geographical range to humid temperate climates. Open canopy habitats, often produced after forest harvesting, are preferred by Pacific Northwest mountain beavers, and populations tend to be less numerous in closed canopy habitat (Hooven 1977; Neal and Borrecco 1981). Sword fern (Polystichum munitum) and salal (Gaultheria shallon) are clipped yearround as a food and bedding source (Neal and Borrecco 1981) and are considered to be important resources for Pacific Northwest mountain beavers (Voth 1968; Allen 1969). Similar Douglas-fir forested habitats in addition to redwood (Sequoia sempervirens) forests are occupied by A. r. humboldtiana in northern California (Steele 1986). Good forage cover (e.g., ferns, forbs, and shrubs) as well as large amounts of small diameter woody debris or uprooted stumps are areas usually selected by mountain beaver (Todd 1992; Hacker and Coblenz 1993; Arjo, unpublished data). Beier (1989) argues that 
mountain beavers have flexible food requirements and that habitat is chosen based on adequate soil drainage and appropriate thermal regimes. Willow (Salix sp.), alder (Alnus sp.) and fir (Abies sp.) dominate areas preferred by mountain beavers in the higher elevations of the Sierra Nevada Mountains.

Unlike the other four subspecies that mostly occur in forested environments, the two southern mountain beaver subspecies occur in primarily coastal scrub, dune scrub and some forested habitats along the northern California coast. Coyotebrush (Baccharis pilularis), salal, blackberry (Rubus spp.), and poison oak (Toxicodendron diversilobum) are common shrubs found in these drier scrub habitats. Associated coniferous forest habitat used by A. r. nigra and A. r. phaea include Douglas-fir, grand fir (Abies grandis) and bishop pine (Pinus muricata). Sword fern and bracken fern (Pteridium aquilinum) are understory plants common in most habitat types occupied by mountain beaver. Habitat degradation from livestock grazing, invasion of exotic plants, fire, and human activities in fragile coastal habitats are factors contributing to the endangered population status of A. r. nigra and the small population size and distribution of $A$. r. pheae (Fitts et al. 2002; Fellers et al. 2004; Wake 2006).

\subsection{2}

\section{Burrow and Nest Structure}

Extensive burrow systems, containing a highly variable number of openings, with high humidity and good soil drainage are used year-round (Voth 1968; Beier 1989). Microclimates within the burrow system are cool and stable with an annual temperature range between 2 and $14^{\circ} \mathrm{C}$ (Johnson 1971) (no SD is provided) and weekly temperature variation rarely fluctuates more than $4^{\circ} \mathrm{C}$ (Johnson 1971). Burrow systems are usually $<120 \mathrm{~cm}$ deep (Camp 1918; Feldhamer et al. 2003); however, older tunnel systems have been documented as deep as $2 \mathrm{~m}$ below the surface. Shallow tunnel systems lead to burrow openings, $15-18 \mathrm{~cm}$ in diameter, which vary in frequency between individual animals. Active burrow systems can be distinguished by fresh pushed dirt, debris, or rocks piled at burrow entrances, and well-established runways firmly packed and smooth from use. In addition, piles of sword fern or other clipped vegetation at burrow entrances are also good indicators of mountain beaver presence. Each mountain beaver system usually contains at least one runway system that leads to an aboveground water source. Mountain beavers also make extensive use of large woody debris piles to supplement above-ground runway systems.

Voth (1968) described five different use chambers within a burrow system: nest, feeding, refuse, fecal pellet, and earth balls. Compacted dirt and rocks are often stored in the earth ball chamber and may be used for 
plugging of burrow entrances (Voth 1968). Mountain beavers are highly dependent upon the nest (or den) chamber which fulfills both reproductive and non-reproductive functions. Nests are usually located $70 \mathrm{~cm}$ below ground and usually under logs, uprooted stumps, logging slash, or thick vegetation (Martin 1971; Arjo, unpublished data). Nests of A. r. nigra were found to be primarily composed of grass and herbaceous vegetation that culminated in a nest cup of iris (Iris douglasiana) leaves (Zielinski and Mazurek 2006). In the Pacific Northwest, mountain beaver nests are composed primarily of sword fern and salal (Camp 1918; Scheffer 1929; Martin 1971; Hooven 1977; Arjo, unpublished data) with the addition of moss to act as a desiccant. These dry, circular nests average $50-60 \mathrm{~cm}$ in diameter and 36-41 cm in height (Martin 1971; Arjo, unpublished data). Only one tunnel leads directly into the nest, and burrow openings are seldom in close proximity to the nest. Adjacent to the nest is usually a feeding and fecal chamber. The feeding chamber contains caches of recently cut or wilted vegetation which is deposited in the refuse chamber when plant matter starts to decay (Feldhamer et al. 2003). Voth (1968) stated that several fecal pellet chambers may be associated with one burrow system and that each may contain pellets at different stages of decomposition.

\subsection{3}

\section{Reproductive Behavior}

Current understanding of mountain beaver social systems documents a solitary existence, with males and females only tolerating one another during breeding season. Male onset of reproductive activity for mountain beaver occurs in November and December (Hubbard 1922; Pfeiffer 1956; Lovejoy et al. 1978; Carraway and Verts 1993). Mountain beavers are monestrous and considered reproductively capable after their second year, and have low reproductive rates (Pfeiffer 1958). In both the A. r. pacifica and A. r. rufa subspecies, breeding usually occurs from late January to early February. Estimated parturition of 2-4 pups after a 28-30 day gestation is late March to early April, with weaning occurring at the beginning of June (Lovejoy and Black 1974; Arjo, unpublished data). Although little data is available on reproduction of the southern subspecies, the large latitudinal range in distribution of mountain beaver may suggest local variation in reproductive traits (Pfeiffer 1958; Zielinski and Mazurek 2006). Early signs of estrous were observed in A. r. nigra which may suggest parturition as early as February (Zielinski and Mazurek 2006). The mating system of the mountain beaver is currently unknown. 


\subsection{4 \\ Population Dynamics}

In older aged forest stands, densities of mountain beaver seldom exceed 4 per ha (Borrecco and Anderson 1980); however, after forest harvest, densities can approach 15-20 per ha (Hooven 1977; Neal and Borrecco 1981). Most of the available data on mountain beaver populations are limited to a few studies conducted on 8-20 year-old reforestation units. Populations in these regeneration sites averaged 3.4-4.6 mountain beaver per ha (Lovejoy and Black 1979b; Neal and Borrecco 1981). Conflict between humans and wildlife occurs mainly in harvested forest units in the Pacific Northwest where management of reforested areas is difficult where mountain beaver populations thrive. Gyug (2000) documented more mountain beaver activity in clear-cuts based on forest harvest method. Units that were harvested with methods that created less ground disturbance often contained more activity. Ground disturbance can cause collapse of the burrow systems and nest chambers that are vital for mountain beaver survival. Recent observations on a unit in western Washington documented a greater population of mountain beaver post-forest harvest than was present prior to harvest in the $>30$-year-old Douglas-fir (Pseudotsuga menziesii) stand (Arjo, unpublished data). In newly reforested units, populations averaging $0.49-2.13$ mountain beaver per ha were documented (Arjo and Nolte 2006). These numbers decreased on one unit the following year after herbicide treatments became effective, but doubled on another unit to 4.38 mountain beavers per ha that was not treated (Arjo and Nolte 2006).

Population estimates for mountain beaver in the southern and eastern extremes of their range, where habitat encompasses non-forested areas, are few (Fellers et al. 2004; Zielinski and Mazurek 2006). Population estimate for A. r. nigra in the $62 \mathrm{~km}^{2}$ range was estimated at 200-500 individuals (USFWS 1998). Limitation to the amount of disturbance these small, isolated populations can sustain precludes more extensive monitoring methods, and limits monitoring of populations to burrow counts which can be highly variable but is currently the best available method.

\subsection{5}

\section{Movements and Home Ranges}

Space use by mountain beavers seems to be influenced by available habitat. Neal and Borrecco (1981) documented smaller home ranges in areas with greater quantities of salal and herbaceous vegetation due to the presence of more stand openings that allowed for growth of the understory. Martin (1971) estimated home ranges in a regenerating forest unit to vary from 
0.03 to $0.2 \mathrm{ha}$ and averaging $0.12 \mathrm{ha}$, and home ranges in late seral stage units were estimated at $0.26 \pm 0.04$ ha (Lovejoy and Black 1979a). Arjo and Nolte (2006) documented home ranges and core areas in newly reforested areas significantly larger than previously reported. Male home ranges averaged $4.16 \pm 0.69$ ha and core areas $0.73 \pm 0.13$ ha in areas where herbicide treatments were used prior to planting seedlings. Female home ranges were similar, although core use areas were slightly larger (1.02 \pm 0.44 ha; Arjo, unpublished data). In areas were herbicide treatments were not conducted prior to planting, home ranges were smaller averaging $1.26 \pm 0.5$ ha for males and $1.7 \pm 0.82$ ha for females. Home ranges can overlap extensively depending on habitat availability with nest sites being defended (Martin 1971; Arjo, unpublished data). Mountain beaver continually explore neighboring runway systems (Nolte et al. 1993). Although telemetry data shows that only one animal occupies a given core area, upon removal of the resident animal, other animals can quickly reinvade a system (Arjo, unpublished data).

\subsection{6}

\section{Forage Preference}

Mountain beavers are strictly herbivorous and are coprophagic, reingesting certain fecal pellets for maximum nutrition (Feldhamer et al. 2003). Areas occupied by mountain beavers can often be identified by stacks of clipped vegetation, also termed "haystack", outside of burrow entrances, called feeder holes. Voth (1968) suggested that this behavior might improve the nutritional quality or succulence of the vegetation, and forage preference is often determined from these haystacked piles of vegetation. In coastal Oregon, food preference for males and females is similar in the summer and fall when bracken fern is preferred, but varies in the winter and spring (Voth 1968). In the winter months, males usually prefer sword fern and lactating females, conifers. Arjo et al. (2004) have documented that preference for conifers is not dependent upon reproductive status. At higher elevations in the Sierra Nevada Range, conifers, red fir (Abies magnifica), dogwood (Cornus spp.), willow (Salix spp.) and corn lily (Veratrum californicum) are preferred, as well as bark and twigs during periods of deep snow (O'Brien 1988; Todd 1992). Vine maple (Acer circinatum), red huckleberry (Vaccinium parvifolium), red alder (Alnus ruba), sword fern, bracken fern, salal, elderberry (Sambucus racemosa), salmonberry (Rubus spectabilis), and Oregon grape (Mahonia aquifolium) are often heavily clipped plant species in the Pacific Northwest (Crouch 1968; Allen 1969; Arjo, personal observation). Angelica (Angelica hendersonii) and iris appear to be a preferred plant species clipped by A. r. nigra and iris was the most common 
species observed in haystacks (Zielinski and Mazurek 2006). Due to their inability to concentrate urine, mountain beaver require a large daily intake of water and succulent vegetation (Pfeiffer et al. 1960; Cafferata 1992). Since mountain beaver require almost one-third of their body weight in water daily (Nungesser and Pfeiffer 1965), it is more likely that haystacks represent drying nesting material and not a food resource.

\section{4}

\section{Management and Economic Impacts}

Mountain beavers are a unique species that fill a biological niche as well as possess intrinsic value as a native animal to the Sierras of California and Pacific Northwest (Steele 1986). Maintaining biological diversity to include an archaic and monotypic species such as the mountain beaver can provide ecological stability. Conservation efforts for the isolated subspecies in the extremes of the range offer challenges to land managers in balancing habitat needs of a single species with recreational opportunities, agriculture and timber production, and urban development. Burrow disturbance in both California, due to human recreation, and Canada, from logging activities (Gyug 2000), can adversely affect mountain beaver populations. However, balancing economic and aesthetic benefits of maintaining recreation areas in Point Arena or Point Reyes, with the need to protect fragile burrow areas, can be difficult. Invasion of exotic plant species threatens areas of coastal scrub habitat vital to mountain beaver; however, little standing water is available most of the year in the Point Arena area and succulent plants provide a readily available source of water. Management of exotic plant species, such as ice plant (Carpobrotus edulis), at Point Arena must be balanced with the reliance of this plant by mountain beaver and potential further disturbance to the habitat (Fitts 1996).

In the northern portion of the range with the exception of Canada, mountain beavers are economically important because of the damage they cause to seedlings, especially Douglas-fir (Hooven 1977; Borrecco and Anderson 1980; Campbell and Evans 1988). Borrecco and Anderson (1980) documented that the majority of recorded mountain beaver damage occurred from the Olympic peninsula to the Puget Sound Trough and the Coast Range to the Willamette Valley, with very little damage occurring in northeast California. In a 1977 survey, over 111,000 ha in the Pacific Northwest, $75 \%$ of that in Douglas-fir stands alone, was damaged by mountain beavers (Borrecco et al. 1979). Depending on tree size, damage by mountain beavers can cause suppression of height growth, reduce stocking in plantations, or delay forest regeneration (Borrecco and Anderson 1980). The most prevalent problem is clipping of seedlings after planting (Hooven 1977; 
Borrecco et al. 1979), where stems up to $19 \mathrm{~mm}$ can be clipped, resulting in a continual loss of trees of up to four years after planting (Lawrence et al. 1961). In addition, basal girdling of 10 - to 20 -year-old trees and undermining of roots in sapling stands can also occur in high density mountain beaver areas (Cafferata 1992).

Historically, managers have implemented both lethal and non-lethal methods to control mountain beaver populations. Lethal trapping is the preferred method used to control mountain beaver populations, and occurs from October through February in both Oregon and Washington prior to seedling planting. Most non-lethal methods, such as box traps, individual tree protectors, and fencing have been only marginally effective. Fencing is ineffective unless wire is buried at least $1.5 \mathrm{~m}$ underground, and even then, some mountain beaver have been known to have deeper burrow systems. Installation of tree barriers can be labor intensive because tubes are placed on the seedlings prior to planting or with an additional crew after planting, and maintenance of the tubes is required to insure integrity. Borrecco and Anderson (1980) documented a significant decrease in damage of seedlings from $3 \%$ to $44 \%$ with the application of tree barriers. However, even with barriers, damage to seedlings can occur. Tubes can be penetrated by mountain beavers, especially those tubes with perforations or seams that allow the mountain beaver to hold onto the plastic (Runde, personal communication). Mountain beavers have also been documented to climb larger tree tubes in order to clip individual seedlings inside the tubes, as well as undermining the tubes (Cafferata 1992).

\section{5}

\section{Conclusion and Future Research Needs}

Mountain beavers offer a unique challenge to land managers where southern and extreme northern populations are protected, yet populations in the largest contiguous range in Oregon and Washington are managed as pests. Understanding mountain beavers, whether in dealing with an endangered or pest species, must begin with a better understanding of the ecology and life history traits across the species' range. The limited, yet diverse distribution of the species offers researchers a rare opportunity for comparative research. For example, Pfeiffer (1958) documented potentially earlier onset of breeding in southern subspecies compared to the Pacific Northwest subspecies. Reproductive information is limited in these small isolated populations, due to their protected status, yet information on exact parturition dates would assist mangers in determining when extra precautions should be implemented for the species' protection. Although, mountain beavers are thought to not be reproductively capable until their second year 
(Pfeiffer 1958), others have documented reproduction in younger individuals (Hacker 1992) in the Pacific Northwest in preferred habitats. Population growth is affected by age of first reproduction and can have significant impacts on management practices when dealing with a pest species, or in trying to manage an isolated, remnant population.

One of the main tools biologists are lacking in working with mountain beavers is an accurate way to determine population size. Current population estimates have been limited to burrow counts usually of active burrows determined from digging or haystacked vegetation (Gyug 2000; Fellers et al. 2004). One of the problems associated with this method is that burrows within an individual home range are highly variable, as is the number of haystack piles associated with an animal. In addition, dense vegetation or large debris piles may preclude monitoring in some areas and therefore bias population estimates. Sword fern monitoring can be used to show activity at burrows, but ferns may not always be taken by resident animals (Engeman et al. 1991; Zielinski and Mazurek 2006; Arjo, unpublished data). Hair snares to determine individual occupancy of burrows has been explored for the Point Arena mountain beaver (Zielinski and Mazurek 2006) and may be successfully used to fragile populations with minimal disturbance.

In addition to population size, dispersal capabilities and limitation to dispersal for mountain beaver, the effects on population are also poorly understood. Timber harvesting appears to limit suitable habitat for immigrating mountain beaver in Canada (Gyug 2000), yet newly harvested areas are preferred by mountain beaver in Washington and Oregon. Understanding if this limitation is due to limited available ecological requirements (e.g., soils, water, habitat types) or a limited source population for immigrants may assist in understanding the limitation of the northern extent of the mountain beaver range.

The diverse distribution of the mountain beaver to areas that in winter are often covered with meters of snow offers a unique opportunity to address foraging requirements. Unfortunately, most information available on food habits is based on older research of a small sample size on pacificaand rufa subspecies (Voth 1968; Allen 1969). Others have documented preferred forage based on availability at feeder holes, which may or may not represent all that the mountain beaver use, and observed clipped vegetation but is usually for limited time period. Using a combination of feeder hole monitoring, clipped vegetation, and remote cameras at feeder holes throughout many seasons may offer a more thorough understanding of forage requirements for the mountain beaver.

Finally, current information on mountain beaver biology and management tools for minimizing damage by mountain beaver is needed for the Pacific Northwest subspecies. Feldhamer et al. (2003) noted that infor- 
mation on the response of mountain beaver populations to sivilcultural activities and a better understanding of populations in association with other habitat characteristics can provide additional direction to management strategies to minimize damage. Additional information on mountain beaver demographics under varying management strategies (e.g., broadcast burning, herbicide treatments, and brush piling) may assist managers in developing integrated pest management strategies that reduce mountain beaver damage.

\section{References}

Allen LO (1969) Preferential food habits of Aplodontia rufa. MSc Thesis. Central Washington State College, Ellensburg, WA

Arjo WM, Nolte DL (2006) Boomer or bust: managing a Pacific Northwest pest species. Proc Vertebr Pest Conf 22 (in press)

Arjo WM, Nolte DL, Harper J, Kimball B (2004) The effects of lactation on seedling damage by mountain beaver. Proc Vertebr Pest Conf 21:163-168

Beier P (1989) Use of habitat by mountain beaver in the Sierra Nevada. J Wildl Manag 53:649-654

Borrecco JE, Anderson RJ (1980) Mountain beaver problems in the forests of California, Oregon, and Washington. Proc Vertebr Pest Conf 9:135-142

Borrecco JE, Anderson HW, Black HC, Evans J, Guenther KS, Lindsey GD, Mathews RP, Moore TK (1979) Survey of mountain beaver damage to forests in the Pacific Northwest, 1977. State of Washington Department of Natural Resources Note 26, p 16

Caffereta S (1992) Silvicultural methods in relation to selected wildlife species. In: Black HG (ed) Silvicultural approaches to animal damage management in Pacific Northwest Forests. USDA Forest Serv Pacific Northwest Res Stat Tech Rep, Portland, OR. PNWGTR-287, pp 231-251

Camp DL (1918) Excavations of burrows of the rodent Aplodontia, with observations on habitat of the animals. Univ Calif Publ Zool 17:517-536

Campbell DL Evans J (1988) Recent approaches to controlling mountain beavers (Aplodontia rufa) in Pacific Northwest forests. Proc Vertebr Pest Conf 13:183-187

Carraway LN, Verts BJ (1993) Aplodontia rufa. Mamm Species 431:1-10

Crouch GL (1968) Clipping of woody plants by mountain beaver. J Mammal 49:151-152

Dalquest WW, Scheffer VB (1945) The systematic status of the races of the mountain beaver (Aplodontia rufa) in Washington. Murrelet 26:34-37

Engeman RM, Campbell DL, Evans J (1991) An evaluation of 2 activity indicators for use in mountain beaver burrow systems. Wildl Soc Bull 19:413-416

Feldhamer GA, Rochelle JA, Rushton CD (2003) Mountain beaver. In: Feldhamer GA, Thompson BC, Chapman JA (eds) Wild mammals of North America: biology, management, and economics. John Hopkins Univ Press, Baltimore, MD pp 179-187

Fellers GM, Pratt D, Griffin JL (2004) Fire effects on the Point Reyes mountain beaver at Point Reyes National Seashore, California. J Wildl Manage 68:502-508

Fitts KM (1996) Observations on use of two non-native plants by the Point Arena mountain beaver. Calif Fish Game 82:59-60

Fitts KS, Flowers S, Jackson R, Marshall D, Meetenmeyer R, Northern P (2002) Point Arena mountain beaver habitat protection and restoration plan for Manchester State Park. California State Parks 
Gyug LW (2000) Status, distribution, and biology of the mountain beaver, Aplodontia rufa, in Canada. Can Field Nat 114:476-490

Hacker AL (1992) Population attributes and habitat selection of recolonizing mountain beaver (Aplodontia rufa). MSc Thesis, Oregon State Univ, Corvallis, OR

Hacker AL, Coblenz BE (1993) Habitat selection by mountain beavers recolonizing Oregon Coast Range clearcuts. J Wildl Manag 57:847-853

Hall ER (1981) The mammals of North America, 2nd edn. Wiley, New York

Hooven EF (1977) The mountain beaver in Oregon: its life history and control. Oregon State Univ Forest Res Lab, Corvallis, OR. Res paper 30

Hubbard CA (1922) Some data upon the rodent Aplodontia. Murrelet 3:14-16

Ingles LG (1959) A quantitative study of mountain beaver activity. Am Mid Nat 61:419-423

Johnson SR (1971) The thermal regulation, microclimate and distribution of the mountain beaver, Aplodontia rufa pacific Merriam. PhD Thesis, Oregon State Univ, Corvallis, OR

Lawrence WH, Kverno NB, Hartwell HD (1961) Guide to wildlife feeding injuries on conifers in the Pacific Northwest. Western Forestry Conserv Assoc, Portland, OR

Lovejoy BP, Black HC (1974) Growth and weight of the mountain beaver, Aplodontia rufa pacifica. J Mammal 55:364-369

Lovejoy BP, Black HC (1979a) Movements and home range of the Pacific mountain beaver (Aplodontia rufa pacifica). Am Mid Nat 101:393-402

Lovejoy BP, Black HC (1979b) Population analysis of the mountain beaver Aplodontia rufa pacifica, in western Oregon. Northwest Sci 53:82-89

Lovejoy BP, Black HC, Hooven EF (1978) Reproduction, growth, and development of the mountain beaver (Aplodontia rufa pacifica). Northwest Sci 52:323-328

Martin P (1971) Movements and activities of the mountain beaver (Aplodontia rufa). J Mammal 52:717-723

Maser C, Mate BR, Franklin JF, Dryness CT (1981) Natural history of Oregon coastal mammals. US Department of Agriculture, Forest Serv, Gen Tech Rep, PNW-133:1-496

McNab BK (1979) The influence of body size on the energetic and distribution of fossorial and burrowing mammals. Ecology 60:1010-1021

Neal FD, Borrecco JE (1981) Distribution and relationship of mountain beaver to openings in sapling stands. Northwest Sci 55:79-86

Nolte DL, Epple G, Campbell DL, Russell JR (1993) Response of mountain beaver (Aplodontia rufa) to conspecifics in their burrow system. Northwest Sci 67:251-255

Nungesser WC, Pfeiffer EW (1965) Water balance and maximum concentrating capacity in the primitive rodent, Aplodontia rufa. Comp Biochem Physiol 14:289-297

O'Brien JP (1988) Seasonal selection of coniferous trees by the sewellel, Aplodontia rufa. Mammalia 52:325-330

Pfeiffer EW (1956) The male reproductive tract of a primitive rodent, Aplodontia rufa. Anat Rec 124:629-635

Pfeiffer EW (1958) The reproductive cycle of the female mountain beaver. J Mammal 39: 223-235

Pfeiffer EW, Nungesser NC, Iverson DA, Wallerius JR (1960) The renal anatomy of the primitive rodent, Aplodontia rufa, and a consideration of its functional significance. Anat Rec 137:227-235

Scheffer TH (1929) Mountain beavers in the Pacific Northwest: their habits, economic status, and control. Farmer's Bulletin 1958. U.S. Department of Agriculture, Washington D.C.

Steele DT (1986) The mountain beaver in California. MSc thesis, UC Davis, Davis, California Taylor WP (1918) Revision of the rodent genus Aplodontia. Univ Calif Publ Zool 17: 435-504

Thrailkill JA, Andrews LS, Claremont RM (2000) Diet of breeding northern goshawks in the Coast Range of Oregon. J Rapt Res 34:339-340 
Todd PA (1992) Mountain beaver habitat use and management implications in Yosemite National Park. Nat Areas J 12:26-31

Toweill DE, Maser C (1985) Food of cougars in the Cascade Range of Oregon. Great Bas Nat 45:77-80

USFWS (1998) Point Arena mountain beaver (Aplodontia rufa nigra [Rafinesque]) recovery plan. Region 1, U.S. Fish and Wildlife Service, Portland, Oregon

Voth E (1968) Food habits of the Pacific mountain beaver, Aplodontia rufa pacifica. $\mathrm{PhD}$ Thesis, Oregon State Univ, Corvallis, OR

Wake TA (2006) Archaeological sewellel (Aplodontia rufa) remains from Duncan's Point Cave, Sonoma County, California. J Mammal 87:139-147

Witmer GW, deCalesta DS (1986) Resource use by unexploited sympatric bobcats and coyotes in Oregon. Can J Zool 64:2333-2338

Zielinski WJ, Mazurek MJ (2006) The reproductive ecology and home range of the Point Arena mountain beaver (Aplodontia rufa nigra). Final Rep USFWS, USDA Forest Serv, Pacific Southwest Res Stat, Arcata, California 